\title{
Effect of temperature and times by hydrothermal carbonization process from sawdust and bagasse for carbon materials supporter
}

\author{
Peerawith Sumtong ${ }^{1 *}$, Nuwong Chollacoop ${ }^{2}$ and Apiluck Eiad-ua ${ }^{1}$ \\ ${ }^{1}$ College of Nanotechnology, King Mongkut's Institute of Technology Ladkrabang, Bangkok, Thailand \\ ${ }^{2}$ National Metal and Materials Technology (MTEC), Pathum Thani, Thailand \\ *E-mail: p.sumtong@gmail.com
}

\begin{abstract}
Carbon supporter from biomass has been fabricated by hydrothermal carbonization due to this process changes the structure of lignocellulose including cellulose, hemicellulose and lignin. The applications from carbon support are gaining in importance due to decreasing supply of fossil fuels and growing environmental concerns. Hydrothermal carbonization process was used to upgrade biomass such as sawdust and bagasse varying temperature at 160 to $200{ }^{\circ} \mathrm{C}$ and varying times at 4 to $24 \mathrm{hr}$ with deionized water $120 \mathrm{ml}$ and $60 \mathrm{ml}$, respectively. The biochars from sawdust and bagasse under hydrothermal carbonization conditions were characterized by Fourier transform infrared spectroscopy (FT-IR). It showed that the most hydroxyl group from this samples was decreased due to cellulose and hemicellulose from biochars were decomposed over than $200^{\circ} \mathrm{C}$. The Biochars yield from sawdust and bagasse by hydrothermal carbonization conditions was determined from weight loss after hydrothermal carbonization process, which is Biochars yield were decreased with increasing hydrothermal carbonization temperature because lignocellulose was decomposed at high temperature and time. The morphology of Biochars were investigated by scanning electron microscope (SEM). It represented the porous structure was inflated to increasing hydrothermal carbonization temperature.
\end{abstract}

Keywords: hydrothermal carbonization, biomass, sawdust, bagasse, carbon supporter

\section{Introduction}

The fossil fuel consumption rate has been increased to industry and household by using from coal, petroleum and natural gas. From this fuel, the disadvantage to environment such as toxic pollution will be causing the global warming. Moreover, the energy derived from fossil fuel will decreasing nowadays and high cost. So, it was interesting trends in the renewable energy are numerous.

The waste biomass was interesting in recent years because the lignocellulose has enormous potential as a feedstock for the production of fuel, heat and electrical power approximate to coal (Liu et al., 2017). Biochemical and thermochemical conversion are two parts techniques used to lignocellulose from waste biomass. Compared with biochemical conversion technique, thermochemical has several advantages such as short processing times and high product yields (Tekin et al., 2014). In addition, thermochemical conversion methods, direct combustion and co-combustion have less risk and inexpensive. From reviews on waste biomass direct combustion conclude that is not a satisfying option due to natural properties of biomass feedstocks such as high moisture and oxygen contents. For example, during combustion to biomass, the high moisture will affect to lowers combustion temperature as well as increase carbon monoxide (CO) emission (Khan et al., 2009; Haykırı-Açma, 2003) causing serious air pollution in atmosphere.

Hydrothermal carbonization is thermochemical conversion for transformation lignocellulose structure including cellulose, hemicellulose, lignin and extractives in waste biomass to obtain biochars with high temperature between $140-220^{\circ} \mathrm{C}$ (Liu et al., 2013; Tekin et al., 2014) and vary times, pressure approximate 10 mbar. It can be generate liquid (bio-oil), gaseous (mainly carbon dioxide), aqueous, and solid products (biochar) (Akhtar \& Amin, 2011). In present most attention is paid to the liquid and gaseous products, but the bio-oil from hydrothermal carbonization cannot be used directly because it is 
the high acidity, complex composition and viscosity. Compared to bio-oil and gaseous products, only a few investigations have been carried out on solid biochar. The biochar is generally produced as a byproduct from waste biomass and high hydrophobicity (Liu et al., 2013; Tekin et al., 2014).

Sawdust is a byproduct of sawmilling. It is a fine powder and toxic waste in factory. Moreover, it can be utilized for example Paul blakeney and fir trees that reacts with $\mathrm{NaOH}$ and $\mathrm{Na}_{2} \mathrm{CO}_{3}$ adsorption of copper $(\mathrm{Cu})$ and zinc $(\mathrm{Zn})$. Moreover, coconut trees that reacts with $\mathrm{H}_{2} \mathrm{SO}_{4}$ absorbs nickel (Ni) and mercury $(\mathrm{Hg})$ ( $\mathrm{Ngah} \&$ Hanafiah, 2008). Bagasse is a similar fiber. It used in the biofuel or the paper industry. In this work, we study the effect of hydrothermal carbonization by varying temperature and time from sawdust and bagasse for carbon supporter.

\section{Materials and methods Materials}

Sawdust and bagasse were selected as the representative waste biomass. The biomass was crushed to less than $5 \mathrm{~mm}$ and dried at $90{ }^{\circ} \mathrm{C}$ for $24 \mathrm{hr}$ for hydrothermal carbonization process.

\section{Preparation}

The biochars from waste biomass (sawdust/bagasse) was prepared by around $30 \mathrm{~g}$ and $15 \mathrm{~g}$ was loaded with $120 \mathrm{ml}$ and $60 \mathrm{ml}$ deionized water into reactor for hydrothermal carbonization. This process was varying temperatures at 160 to $200{ }^{\circ} \mathrm{C}$ and times at 4 to $24 \mathrm{hr}$. After that the biochars were quickly cooled down at room temperature and dried at $90^{\circ} \mathrm{C}$ for $24 \mathrm{hr}$.

\section{Characterization}

The morphology of biochars (sawdust and bagasse) were characterized by scanning electron microscope (SEM) on EVO ${ }^{\circledR}$ MA10. The functional group were determined by Fourier transform infrared spectroscopy (FT-IR) technique in the wave number range of $4000-400 \mathrm{~cm}^{-1}$. The yield of biochars were calculated from weight lossed of biochars under hydrothermal carbonization process compared with weight of raw biomass. Finally, the carbon content of biochars were investigated via $\mathrm{CHN}$ analyser.

\section{Results and discussion}

The Morphology of biochars under hydrothermal carbonization were characterized by SEM images. Figure 1 and Figure 2 show SEM images of sawdust biochar and bagasse biochar with different temperature from $160-200^{\circ} \mathrm{C}$ for $24 \mathrm{hr}$. Change in temperature were found to affect the morphology such as larger porous structure at increase temperature and time (Deng et al., 2016). This is because of increasing temperature and time in process will decompose the lignocellulose in biomass (Tekin et al., 2014). Cellulose and hemicellulose structures can be eliminated from the surface by hydrolysis reaction (Zhao et al., 2014; Kapu and Trajano, 2014) in hydrothermal process.
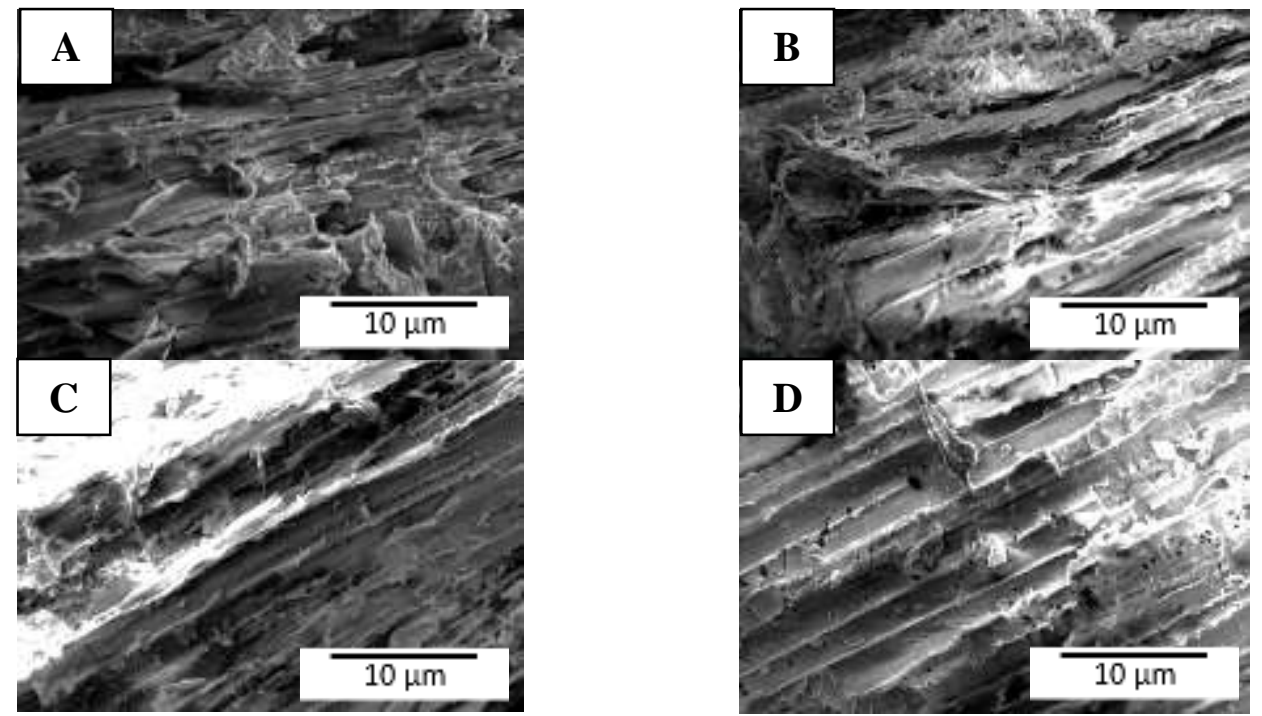

Figure 1. The biochars (sawdust) from hydrothermal carbonization conditions at (A) raw, (B) $160^{\circ} \mathrm{C},(\mathrm{C})$ $180^{\circ} \mathrm{C}$, and (D) $200^{\circ} \mathrm{C}$ for $24 \mathrm{hr}$. 

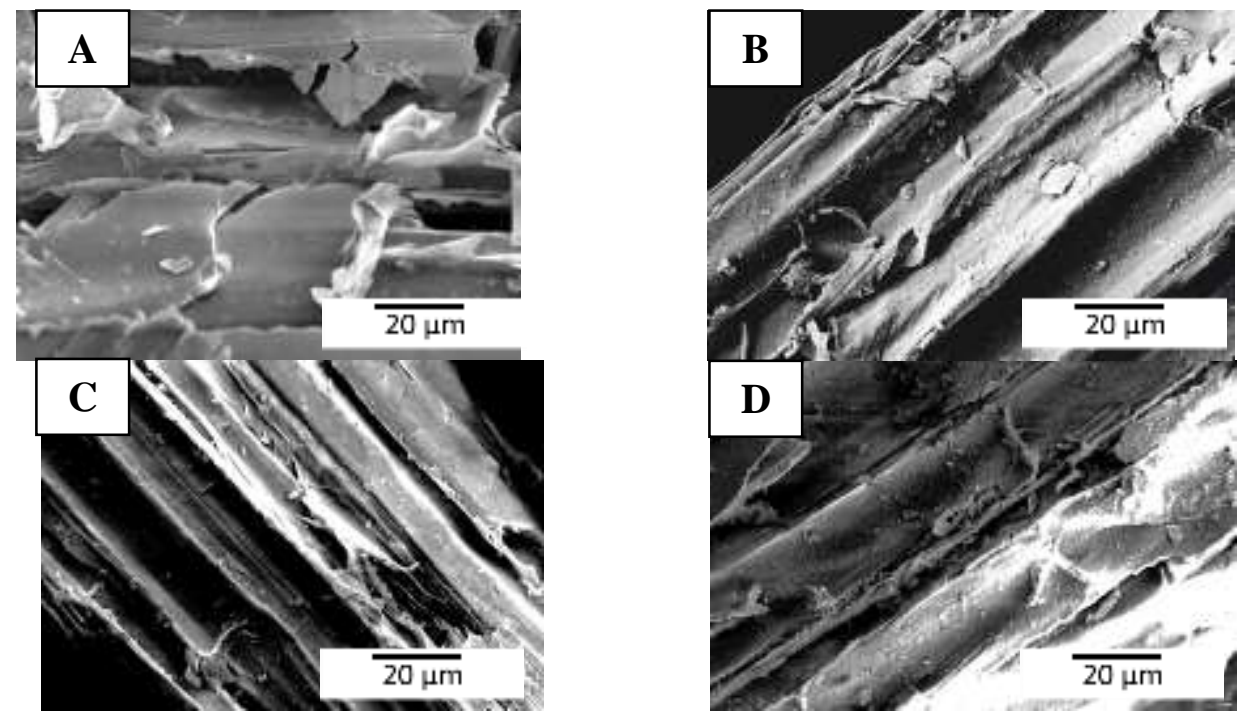

Figure 2. The biochars (bagasse) via hydrothermal carbonization conditions at (A) raw, (B) $160^{\circ} \mathrm{C}(\mathrm{C})$ $180^{\circ} \mathrm{C}$, and (D) $200^{\circ} \mathrm{C}$ for $24 \mathrm{hr}$.

The functional group in biochars were investigated by Fourier transform infrared spectroscopy (FT-IR). Figure 3 show the functional group of sawdust and bagasse at different hydrothermal carbonization from $160-200^{\circ} \mathrm{C}$ for $24 \mathrm{hr}$. At $3680-3000 \mathrm{~cm}^{-1}$ was indicated to $\mathrm{OH}$ group of cellulose, hemicellulose and lignin. At $2917 \mathrm{~cm}^{-1}$ indicated to $-\mathrm{CH}$ alkane group of lignin peak. At $1715 \mathrm{~cm}^{-1}$ indicated to $C=O$ group of hemicellulose. At $1634-1328 \mathrm{~cm}^{-1}$ indicated to lignin peak. At $1210-1080 \mathrm{~cm}^{-1}$ indicated to bending of $\mathrm{C}-\mathrm{O}$ peak in hemicellulose. Increasing of time and temperature resulted in hydroxyl group, Lignin and $\mathrm{C}-\mathrm{O}$ peak decreased. The hydroxyl group $(-\mathrm{OH})$ of cellulose, hemicellulose and lignin were decreased with hydrothermal temperature due to deoxygenation and dehydration reaction. It can be eliminated $\mathrm{O}_{2}$ and $\mathrm{H}_{2} \mathrm{O}$ contents for biochar production. As a result biochars are increase hydrophobicity (Liu et al., 2013). Lignin peak at $1634-1328 \mathrm{~cm}^{-1}$ is slightly change from aromatization reaction because lignin consists of the most aromatic rings is high stability and degradation approximate $300^{\circ} \mathrm{C}$. While bending of C-O peak of hemicellulose at $1210-1080 \mathrm{~cm}^{-1}$ was reduced dramatically due to hemicellulose is less stable than lignin. Moreover, the $\mathrm{C}-\mathrm{O}$ peak component are depend on the type of biomass.
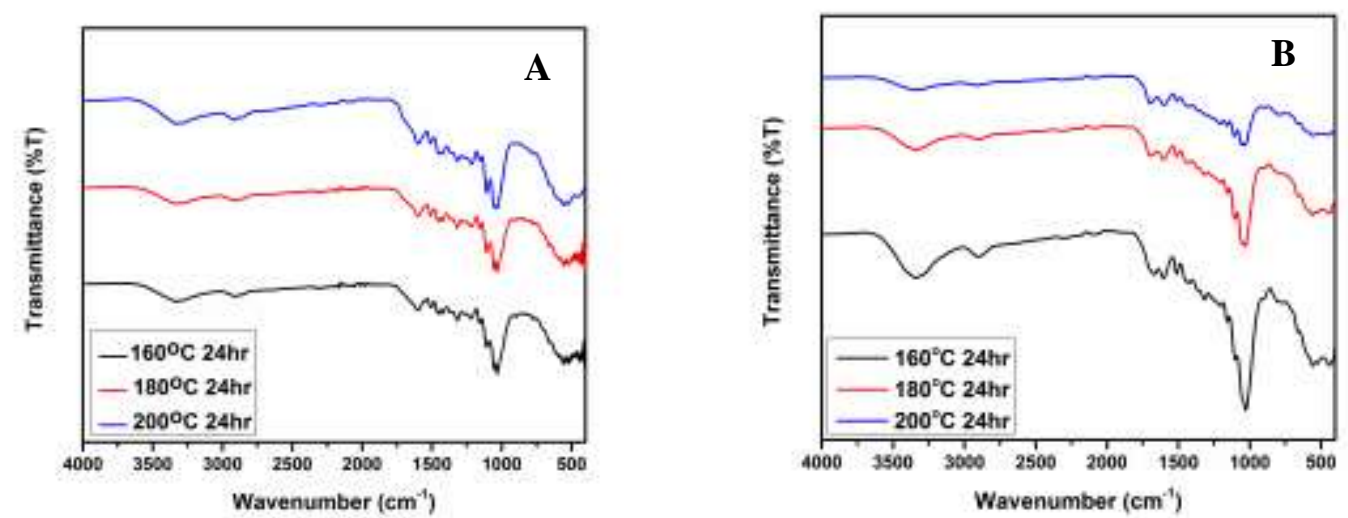

Figure 3. FT-IR spectrum after hydrothermal carbonization conditions by vary times and temperatures (A) sawdust and (B) bagasse. 
The biochars yield from sawdust and bagasse in Figure 4 were slightly decreased with increasing of hydrothermal carbonization temperature from 160 to $200{ }^{\circ} \mathrm{C}$ and time from 4 to $24 \mathrm{hr}$. Due to cellulose and hemicellulose contents in lignocellulose were decomposed and eliminated during hydrothermal carbonization by hydrolysis reaction. Hydrolysis can be destroyed structure and chemical composition of cellulose and hemicellulose (polymer structure) to monomer structure (Zhao et al., 2014; Kapa \& Trajano, 2014). Futhermore, the loss yields from biochars with hydrolysis reaction can be converted to solid liquid and gas (Tekin et al., 2014).
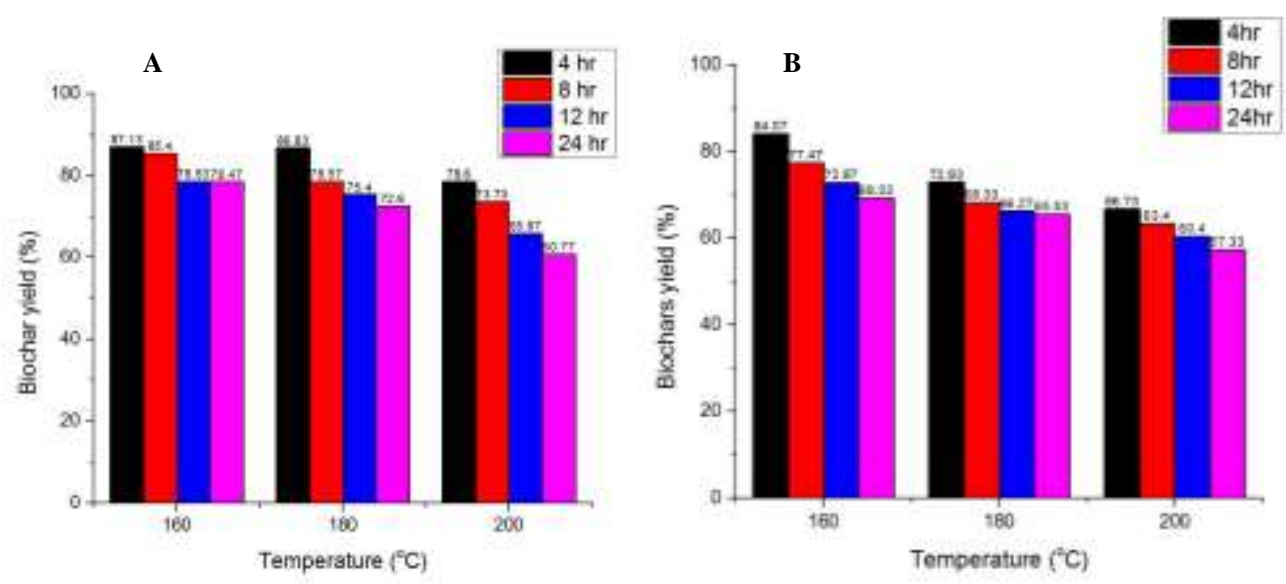

Figure 4. Yield of biochars from hydrothermal carbonization with different temperature and time $(A)$ sawdust and (B) bagasse.

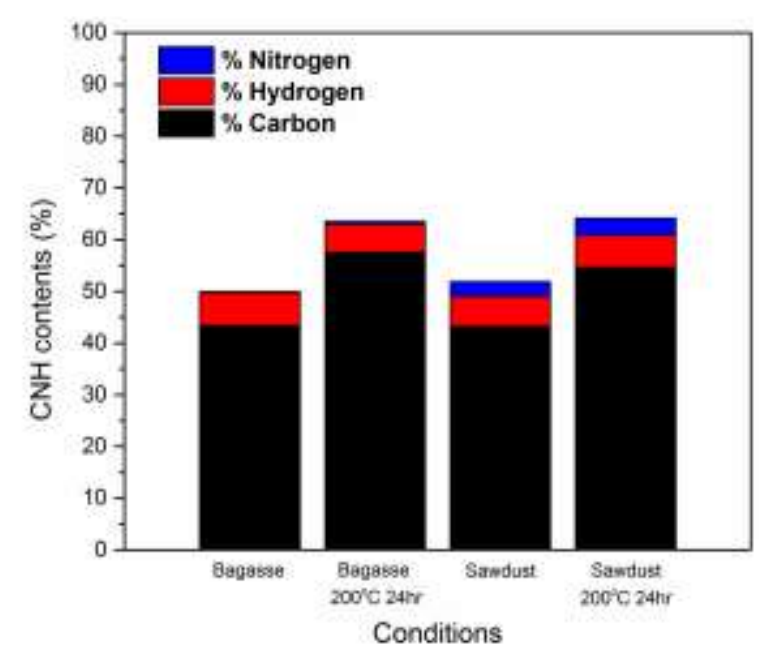

Figure 5. CHN elemental analyzer of biochars with hydrothermal carbonization.

The CHN element of biochars were reported about increasing carbon content via using hydrothermal carbonization. In Figure 5, carbon content of bagasse conditions (raw and $200{ }^{\circ} \mathrm{C} 24 \mathrm{hr}$ ) were $43.35 \%$ and $57.53 \%$, respectively while sawdust conditions were $43.23 \%$ and $54.65 \%$, respectively. Increasing carbon content is due to the different chemical composition of sawdust and bagasse also cellulose, hemicellulose and lignin (Garrote et al., 1999).

\section{Conclusion}

Biochars from using sawdust and bagasse have been successfully produced with hydrothermal carbonization process. Yield of biochars under hydrothermal carbonization were decreased due to cellulose and hemicellulose in lignocellulose were almost totally decomposed with increasing temperature and time. Deoxygenation and dehydration reaction causes biochars to have hydroxyl group decreased. 
But lignin content has slightly changed because the temperature is too low. Finally, the optimum conditions from hydrothermal carbonization is bagasse $200^{\circ} \mathrm{C}$ for $24 \mathrm{hr}$ because it is the less hydroxyl group, C-O peak of hemicellulose and carbon content.

\section{Acknowledgements}

This work was financially supported by the Research and Researcher for Industry (RRi), The Thailand Research Fund (TRF) and also thankful to Nanoporous Materials Research Laboratory at College of Nanotechnology, King Mongkut's Institute of Technology Ladkrabang for their supporting.

\section{References}

Akhtar, J. \& Amin, N. A. S. (2011). A review on process conditions for optimum bio-oil yield in hydrothermal liquefaction of biomass. Renewable and Sustainable Energy Reviews, 15(3), 16151624.

Deng, J., Xiong, T., Wang, H., Zheng, A. \& Wang, Y. (2016). Effects of cellulose, hemicellulose, and lignin on the structure and morphology of porous carbons. ACS Sustainable Chemistry \& Engineering, 4(7), 3750-3756.

Garrote, G., Dominguez, H. \& Parajo, J. C. (1999). Hydrothermal processing of lignocellulosic materials. European Journal of Wood and Wood Products, 573), 191-202.

Haykırı-Açma, H. (2003). Combustion characteristics of different biomass materials. Energy Conversion and Management, 44(1), 155-162.

Sella Kapu, N. \& Trajano, H. L. (2014). Review of hemicellulose hydrolysis in softwoods and bamboo. Biofuels, Bioproducts and Biorefining, 8(6), 857-870.

Khan, A. A., De Jong, W., Jansens, P. J. \& Spliethoff, H. (2009). Biomass combustion in fluidized bed boilers: potential problems and remedies. Fuel processing technology, 90(1), 21-50.

Liu, Z., Quek, A., Hoekman, S. K. \& Balasubramanian, R. (2013). Production of solid biochar fuel from waste biomass by hydrothermal carbonization. Fuel, 103, 943-949.

Ngah, W. W. \& Hanafiah, M. A. K. M. (2008). Removal of heavy metal ions from wastewater by chemically modified plant wastes as adsorbents: a review. Bioresource technology, 99(10), 39353948.

Tekin, K., Karagöz, S. \& Bektaş, S. (2014). A review of hydrothermal biomass processing. Renewable and sustainable Energy reviews, 40, 673-687.

Zhao, Y., Lu, W., Chen, J., Zhang, X. \& Wang, H. (2014). Research progress on hydrothermal dissolution and hydrolysis of lignocellulose and lignocellulosic waste. Frontiers of Environmental Science \& Engineering, 8(2), 151-161. 